\title{
Paget's Breast Disease- A Diagnostic Dilemma: A Case Report with Review
}

\author{
Ashwani Gupta, Mukta Pujani and Sunder Goyal* \\ Head of Surgery, ESIC Med College \& Hospital, NIT, Faridabad, India \\ *Corresponding author: Sunder Goyal, Head of Surgery, ESIC Med College \& Hospital, NIT, Faridabad, India
}

\begin{tabular}{|c|c|}
\hline ARTICLE INFO & ABSTRACT \\
\hline Received: 幽 April 19, 2021 & $\begin{array}{l}\text { Paget's breast disease (PBD) is a rare disease with an unusual presentation, so early } \\
\text { diagnosis is quite difficult. Only histopathology can give the definitive diagnosis, and }\end{array}$ \\
\hline Published: 㓞 May 04, 2021 & $\begin{array}{l}\text { the treatments depend upon the presence or absence of associated breast lump. Simple } \\
\text { lumpectomy, mastectomy, or radical mastectomy depend upon the lump (cancer) in the }\end{array}$ \\
\hline
\end{tabular}
agnostic Dilemma: A Case Report with Review. Biomed J Sci \& Tech Res 35(3)-2021. BJSTR. MS.ID.005717.

\section{Introduction}

Sir Paget first described Paget's disease of the nipple in 1874. It is a malignant disease that presents itself as eroding and bleeding ulcer of the nipple and areola. It may be an extension of underneath ductal breast adenocarcinoma. Microscopically, typical large clear cells (Paget's cells) with pale and abundant cytoplasm and hyperchromatic nuclei with prominent nucleoli are seen in the epidermal layer. Paget's disease is mostly accompanied by primary invasive or in situ carcinoma of the breast [1]. PDB presents most commonly in postmenopausal women between 50 and 60 years old, with a median age of 56-57 [2,3]. PDB involving the nipple has been commonly associated with IDC and is thought to be because of epidermal extension of underlying ductal breast carcinoma [46]. Ultrasounds, mammography, and magnetic resonance imaging can search for underlying cancer and guide surgical management. A biopsy is mandatory to confirm the diagnosis, particularly in cases without an associated lump. The surgical treatment of Paget's disease is not clear, whether radical or conservative. Palpable mass and the invasiveness of cancer predict and decide about prognosis [7]. Our case is classical for PDB without any lump underneath managed conservatively with radiation.

\section{Case Presentation}

The 61-year-old female with no family history of cancer presented with eczema and eroded the right nipple for the last year.
The examination revealed an eczematous aspect of the right breast with an eroded nipple suggesting Paget's disease (Figure 1). There was no palpable breast mass and no axillary lymphadenopathy. An ultrasound and mammograms of breasts did not reveal any lump. Biopsy concluded PDB (Figure 2). Tissue was negative for Estrogen, Progesterone and HER2 receptors. Lumpectomy was done along with postoperative radiation.

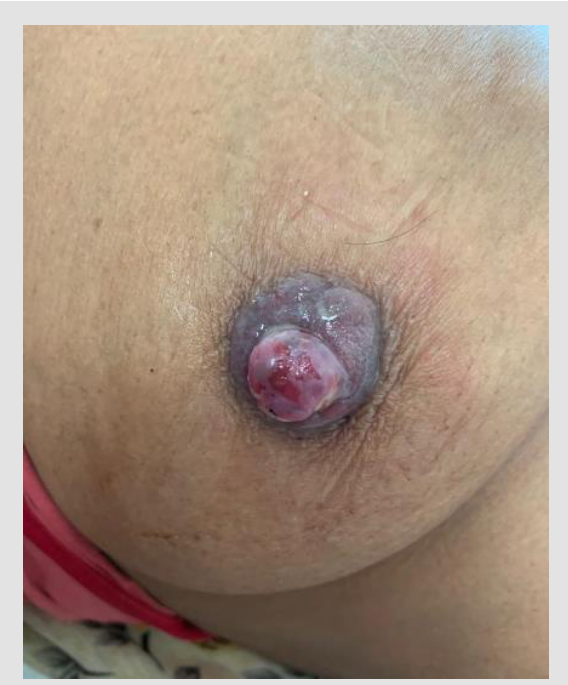

Figure 1: Photo of the diseased right breast. 


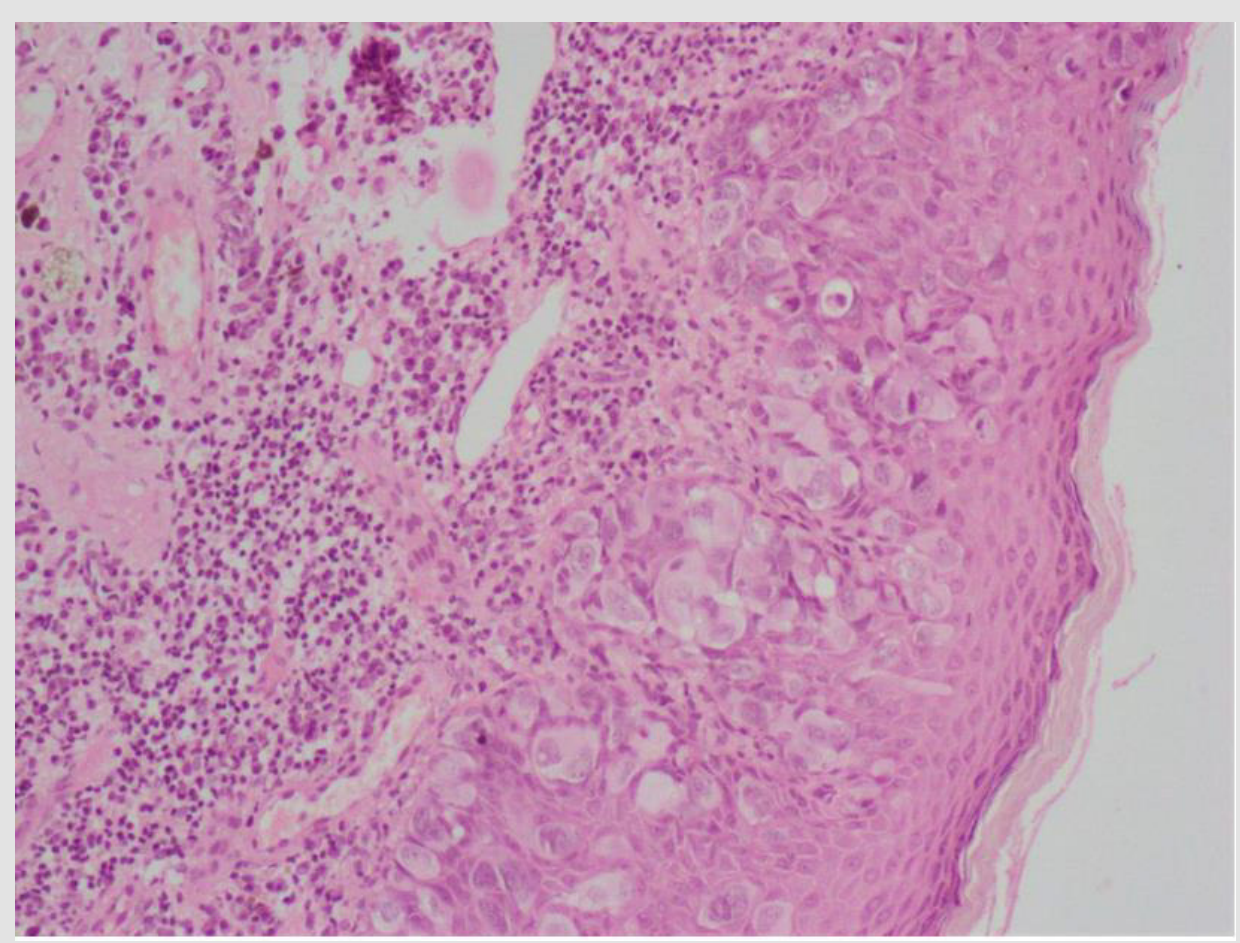

Figure 2: Histopathology slide of PBD.

\section{Discussion}

The common age for PBD is about 50-70 years, but uncommon cases have been reported in their 20s. Paget's disease was reported in 1,874 by James Paget as an eczematous lesion of the nipple with or without an underlying lump. Paget's breast disease is a malignant disease that starts as eroding and bleeding ulcer of the nipple. It may be an extension of ductal breast adenocarcinoma. Histopathologically slide is full of large clear cells (Paget's cells) with pale and abundant cytoplasm and hyperchromatic nuclei with prominent nucleoli. The breast's primary invasive or in situ carcinoma may be associated with Paget's nipple disease [8]. Immunohistochemistry of Paget cells and underlying cancer may show a more aggressive, HER2-enriched, molecular subtype of breast cancer [9]. Paget's disease of the nipple develops slowly without any early symptom. Mostly it starts as an eczematous erythema oozing patch of one side nipple first and then slowly start involving and spread centrifugally to invade the areola and the adjacent skin. The colour of the skin changes from pink to red. Retraction, ulceration, or bleeding of the nipple occurs as the disease progress. Some women have a burning sensation, tingling, increased sensitivity, and pain in the disease's late-stage due to serious skin destruction. Lumps or masses in the same breast occur in more than $50 \%$ of the patients. The symptoms may wax and wane along with redness, oozing, crusting, and a nonhealing nipple sore.

Paget cells are characteristics of PBD. These cells are large cells with clear cytoplasm (clear halo) and eccentric, hyperchromic nuclei found throughout the epidermis [10]. There is disagreement about the source of these cells. It is unclear whether these cells arise from the breast's ductal system or result from in situ malignant transformations $[10,11]$. According to the widely accepted migratory theory, the ductal carcinoma in situ cells from the original tumour travel through milk ducts to the nipple and its surrounding skin. Cancer cells disturb the normal epithelial barrier, and extracellular fluid builds up on the skin's surface and cause the crusting of the areola skin [11]. Paget cells possess glandular cells' features and show positivity for HER2 oncogene. The exact mechanisms are not clear, but interactions between heregulin-alpha protein produced by nipple epidermal keratinocytes and HER2 on the tumour cells have been drawn in the chemotaxis.

\section{Staging}

a) If underlying carcinoma is identified, staging is based on its features. The presence of Paget disease does not influence staging.

b) If no underlying carcinoma is identified, the stage is Tis (Paget's)

\section{Diagnosis}

A nipple biopsy is essential for the diagnosis of PBD. Wedge biopsy is ideal (a blade is used to remove a small wedge of the nipple and eczematous skin). This is most informative as a good amount of tissue is available. Most people who have PBD also have one or more tumours inside the same breast. In addition to a nipple biopsy, a clinical breast exam breast is carried out to check for lumps or other breast changes. About 50 per cent of patients with PBDs 
have an associated breast lump that can be felt in a clinical breast exam. An ultrasound exam, or mammogram, or magnetic resonance imaging scan is mandatory in cases with a palpable lump in the breast [12]. Mammogram is normal in patients with only nipple changes without a clinically palpable mass, as in our case $[3,6,13]$. The immunohistochemistry is essential to distinguish Paget cells from other cell types like Toker cells which are normally present and can be difficult to distinguish from Paget's disease [14]. CD138 and p53 are used as positive in Paget's disease and negative in normally present Toker cells. Also, Paget cells stain positive for CK7 in $>90 \%$ of the cases. Likewise, GATA3 and HER-2 are expressed in around $90 \%$ of the cases and are used for confirmation, including CK7 negative Paget disease [15].

Our case highlights the importance of histologic examination via incisional or deep punch biopsy to confirm PDB diagnosis, regardless of a prior normal mammogram or breast ultrasound. Most patients with PBD without a palpable mass will have a normal mammogram as in our case $[3,6,13]$. The mammography is useful and sensitive to detect underlying carcinoma associated with PDB [2,13]. Magnetic resonance imaging (MRI) is highly sensitive for detecting breast cancer, especially in patients with a normal mammogram [2]. However, negative radiological studies alone cannot rule out PDB in a patient presenting with cutaneous nipple changes. The nipple changes should be correlated with biopsy and clinical findings to establish a PDB diagnosis. A punch or wedge biopsy of the nipple should be performed to take a full thickness of the nipple and areola to ascertain the diagnosis. Usually, a shave biopsy of the nipple is inadequate tissue to establish the diagnosis. A repeat biopsy or excision of the nipple may be necessary if the tissue sample is inadequate during first biopsy [2].

\section{Treatment}

Till recently, mastectomy with or without the removal of axillary lymph nodes on the same side was looked upon as the standard surgery for PBD. Most patients were associated with tumours inside the same breast $[16,17]$. Even if only one tumour was present, that tumour could be located several centimetres away from the nipple and areola. It would not be removed by surgery on the nipple and areola alone [16,17]. However, in patients with PBD without a lump with negative mammograms, breast-conservative surgery (BCS) followed by whole breast radiation therapy may be the treatment of choice. Breast conservative surgery is a harmless substitute for mastectomy. Its necessity is clear surgical margins and postoperative adjuvant radiotherapy. When BCS is considered, it is mandatory to exclude breast cancer preoperatively by clinical, radiological and histopathological examination [13,16,17]. In patients with PBD with a breast tumour- a mastectomy with sentinel lymph node biopsy should be done to find spread in axillary lymph nodes. Axillary clearance is done if the sentinel node is positive
$[18,19]$. Adjuvant therapy, consisting of chemotherapy and/or hormonal therapy, may also be advocated depending upon the stage, positive lymph nodes, estrogen and progesterone receptors in tissue and HER2 protein expression in the tumour cells.

\section{Prognosis}

The prognosis of PBD depends upon the following factors:

a) Whether a tumour is present in the affected breast or no tumour on clinical and radiological examination

b) If one or more tumours are present in the affected breast, whether those tumours are DIC in situ or invasive breast cancer.

c) The stage of that cancer is the case of invasive breast carcinoma $[16,20,21]$.

\section{Conclusion}

Diagnosis of PBD in the early stage is a diagnostic dilemma. It is uncommon breast cancer which is mostly accompanied by breast cancer. In PBD cases with normal ultrasound and mammogram, a wedge biopsy of the nipple is essential to establish the diagnosis. Management of PBD depends upon the presence or absence of an underneath lump. Patients with Paget's disease are candidates for breast conservation with appropriate preoperative investigations. Surgical consequences are equal to those of mastectomy if free surgical margins are achieved and postoperative adjuvant radiotherapy.

\section{References}

1. Dubar S, Boukrid M, Bouquetde Joliniere J, Guillou L, Vo QD, Major A, et al. (2017) Paget's Breast Disease: A Case Report and Review of the Literature. Front Surg 4: 51.

2. Karakas C (2011) Paget's disease of the breast. Journal of Carcinogenesis 10: 31 .

3. Wong G, Drost L, Yee C, Lam E, McKenzie E, et al. (2019) Are we properly diagnosing and treating Paget's disease of the breast? A case series. Journal of Pain Management 12(2): 169-172.

4. Challa VR, Deshmane V (2015) Challenges in diagnosing and managing Paget's disease of the breast-A retrospective study. Indian Journal of Surgery 77(Suppl. 3): 1083-1087.

5. Ackerman L, Rosai J, Goldblum J, Lamps L, McKenney J, et al. (2018) Rosai and Ackerman's surgical pathology (11 ${ }^{\text {th }}$ Edn.), Philadelphia, PA: Elsevier.

6. Aguayo-Carreras P, Bonilla-García L, Pérez-López I, Cuenca-Barrales C, Tercedor-Sánchez J, et al. (2017) Paget's disease of the breast: A dangerous imitator of eczema. Sultan Qaboos University Medical Journal 17(4): e487-e488.

7. Bolognia J, Schaffer J V, Cerroni L (2018) Dermatology (4 $4^{\text {th }}$ Edn.), Elsevier.

8. Brickley, Sylvana A. Mercurio, Mary Gail (2020) Paget's Disease of the Breast Presenting as Nipple Ulceration with Normal Mammogram. Journal of the Dermatology Nurses' Association: 5/6 2020 -12(3): 121123.

9. Alvero R (2017) Paget's disease of the breast. Ferri's Clinical Advisor 2017. Philadelphia: Elsevier Health Sciences, pp. 915. 
10. Arafah M, Arain SA, Raddaoui EM, Tulba A, Alkhawaja FH, et al. (2019) Molecular subtyping of mammary Paget's disease using immunohistochemistry. Saudi Medical Journal 40 (5): 440-446.

11. Marques-Costa JC, Cuzzi T, Carneiro S, Parish LC, Ramos-e-Silva M, et al (2012) Paget's disease of the breast. Skinmed. 10 (3): 160-165. quiz 165

12. Kumar V (2007) Robbins basic pathology (8 ${ }^{\text {th }}$ Edn.), Philadelphia: Saunders/Elsevier. p. 746. ISBN 978-1-4160-2973-1.

13. Caliskan M, Gatti G, Sosnovskikh I, Nicole Rotmensz, Edoardo Botteri, et al. (2008) Paget's disease of the breast: the experience of the European Institute of Oncology and review of the literature. Breast Cancer Research and Treatment 2008; 112(3): 513-521.

14. Helme S, Harvey K, Agrawal A (2015) Breast-conserving surgery in patients with Paget's disease. British Journal of Surgery 102(10): 11671174 .

15. Di Tommaso L, Franchi G, Destro A, Broglia F, Minuti F, et al. (September 2008) Toker cells of the breast. Morphological and immunohistochemical characterization of 40 cases. Human Pathology 39 (9): 1295-300.

16. Arain SA, Arafah M, Said Raddaoui EM, Tulba A, Alkhawaja FH, et al. (March 2020). "Immunohistochemistry of mammary Paget's disease. Cytokeratin 7, GATA3, and HER2 are sensitive markers". Saudi Medical Journal 41 (3): 232-237.

ISSN: 2574-1241

DOI: 10.26717/BJSTR.2021.35.005717

Sunder Goyal. Biomed J Sci \& Tech Res

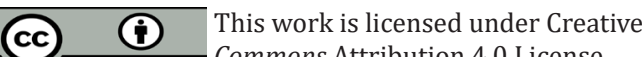

Submission Link: https://biomedres.us/submit-manuscript.php
17. Kanitakis J Mammary (2007) extramammary Paget's disease. Journal of the European Academy of Dermatology and Venereology 2007; 21(5): 581-590.

18. Kawase K, Dimaio DJ, Tucker SL, Thomas A Buchholz, Merrick I Ross, et al. (2005) Paget's breast disease: there is a role for Breast-conserving therapy. Annals of Surgical Oncology 12(5): 391-397.

19. Sukumvanich P, Bentrem DJ, Cody HS (2007) The role of sentinel lymph node biopsy in Paget's disease of the breast. Annals of Surgical Oncology 14(3): 1020-1023.

20. Laronga C, Hasson D, Hoover S, John Cox, Alan Cantor, et al. (2006) Paget's disease in the era of sentinel lymph node biopsy. American Journal of Surgery 192(4): 481-483.

21. Ries LAG, Eisner MP (2012) Cancer of the Female Breast. In: Ries LAG, Young JL, Keel GE, et al., editors. SEER Survival Monograph: Cancer Survival Among Adults: U.S. SEER Program,1988-2001, Patient and Tumor Characteristics. Bethesda, MD: National Cancer Institute, SEER Program, 2007. Retrieved April 10, 2012.

22. Chen Cy, Sun LM, Anderson BO (2006) Paget's disease of the breast: changing patterns of incidence, clinical presentation, and treatment in the U.S. Cancer 107(7): 1448-1458.

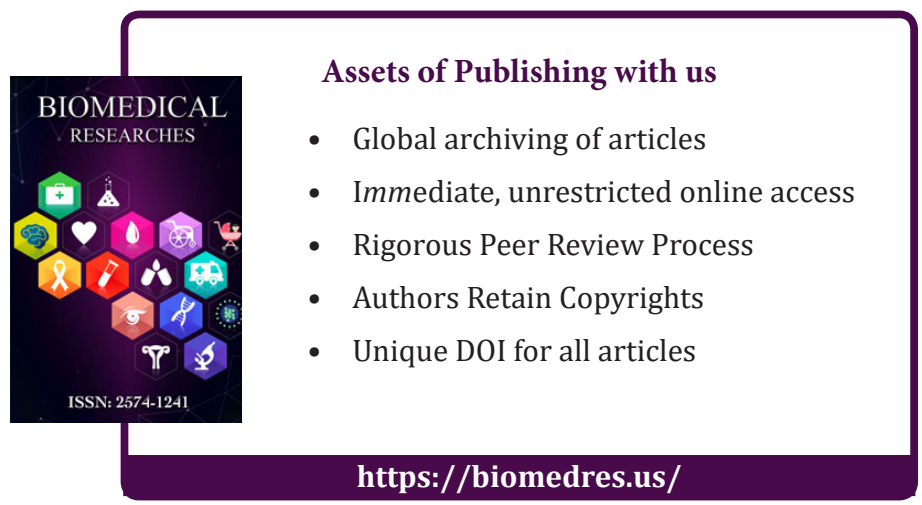

